\title{
Tratamento de vasculopatia livedóide com imunoglobulina intravenosa
}

\author{
Treatment of Livedoid Vasculopathy with intravenous \\ immunoglobulin "
}

\author{
Jader Freire Sobral Filho $^{1} \quad$ Milane Caroline de Oliveira Valdek $^{2} \quad$ Luiza Toscano Dias Rodrigues $^{3}$
}

\begin{abstract}
Resumo: A vasculopatia livedóide apresenta-se com dor e úlceras de cicatrização lenta em membros inferiores, e fisiopatologia obscura. As estratégias terapêuticas incluem cicatrizantes, antiinflamatórios e imunossupressores, sem relatos de benefício permanente. Administrou-se imunoglobulina em paciente refratário a outras terapias e avaliou-se o comprometimento da pele antes e depois por meio de escore clínico. Houve regressão significativa das lesões. A droga foi bem tolerada, e a terapia foi finalizada.

Palavras-chave: Dermatopatias vasculares; Imunoglobulinas endovenosas; Resultado de tratamento

Abstract: Livedoid vasculopathy presents with pain and slowly healing ulcerations of the lower limbs, and has obscure pathophysiology. Usual therapeutics include rheologic, anti-inflammatory and immunosuppressing agents with no reports of permanent benefits. Immunoglobulin was administered to a patient who was refractory to other treatments and skin involvement was assessed by means of clinical score before and after treatment. There was a significant healing of the lesions. Imunoglobulim was well tolerated and therapy was discontinued.

Keywords: Immunoglobulin, intravenous; Skin diseases, vascular; Treatment outcome
\end{abstract}

A vasculopatia livedóide (VL) é enfermidade rara, crônica, recorrente e localizada na região inferior de pernas, tornozelo e porção posterior do pé. Observamse máculas purpúricas, pápulas, bolhas hemorrágicas e úlceras dolorosas, evoluindo para cicatrizes atróficas de cor branca, piorando no verão e remitindo no inverno. A fisiopatologia da VL não está definida, sendo os processos vasculíticos e as vasculopatias trombo-oclusivas a base da doença na derme e epiderme. ${ }^{1-3}$

Na histopatologia observam-se hialinização segmentar, proliferação endotelial, deposição de fibrina e formação de trombos na derme papilar e reticular superficial. Anormalidades na coagulação sistêmica parecem estar envolvidas em mecanismos fisiopatológicos. Têm sido descritas a deficiência concomitante de vitamina $\mathrm{C}$, mutação do fator $\mathrm{V}$ e mutação do gene da protrombina. ${ }^{4-6}$

A imunoglobulina intravenosa (Igiv) tem sido bem-sucedida na terapia das doenças vasculares do colágeno. A VL é refratária à maioria dos tratamentos usuais (cicatrizantes, antiinflamatórios e imunossupressores), e a Igiv foi previamente utilizada na VL com sucesso terapêutico. ${ }^{7 \cdot 9}$

Paciente de 17 anos de idade, do sexo masculino, cor branca. Referia história de lesões dolorosas e ulceradas (Figura 1) nos membros inferiores há 10 meses, tendo feito uso de diversos medicamentos (pentoxifilina, ciprofloxacina, penicilina benzatina, sulfonas, antisépticos locais e prednisona $60 \mathrm{mg}$ ) sem apresentar melhora. Ao exame físico, apresentava máculas purpúri-

Recebido em 31.08.2005.

Aprovado pelo Conselho Consultivo e aceito para publicação em 30.06.2008

* Trabalho realizado no Serviço de Dermatologia do Hospital Universitário Lauro Wanderley da Universidade Federal da Paraíba (UFPB) - João Pessoa (PB), Brasil. Conflito de interesse: Nenhum / Conflict of interest: None

Suporte financeiro: Nenhum / Financial funding: None

Professor adjunto e chefe do Serviço de Dermatologia da Universidade Federal da Paraíba (UFPB) - João Pessoa (PB), Brasil

Aluna do curso de graduação em Medicina da Universidade Federal da Paraíba (UFPB) - João Pessoa (PB), Brasil.

Aluna do curso de graduação em Medicina da Universidade Federal da Paraíba (UFPB) - João Pessoa (PB), Brasil.

(C)2008 by Anais Brasileiros de Dermatologia

An Bras Dermatol. 2008;83(4):372-4. 


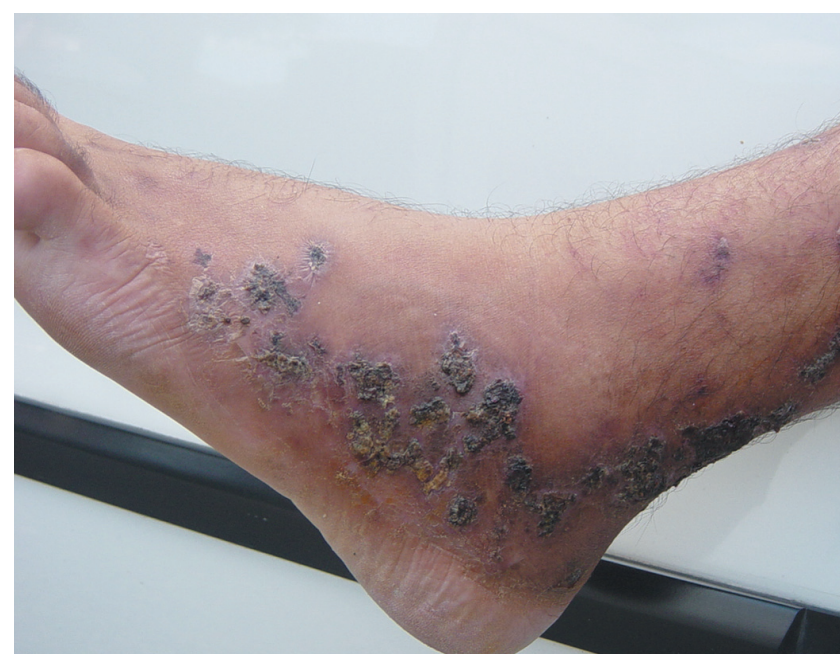

FigurA 1: Numerosas úlceras envoltas por áreas eritematosas e purpúricas antes do tratamento

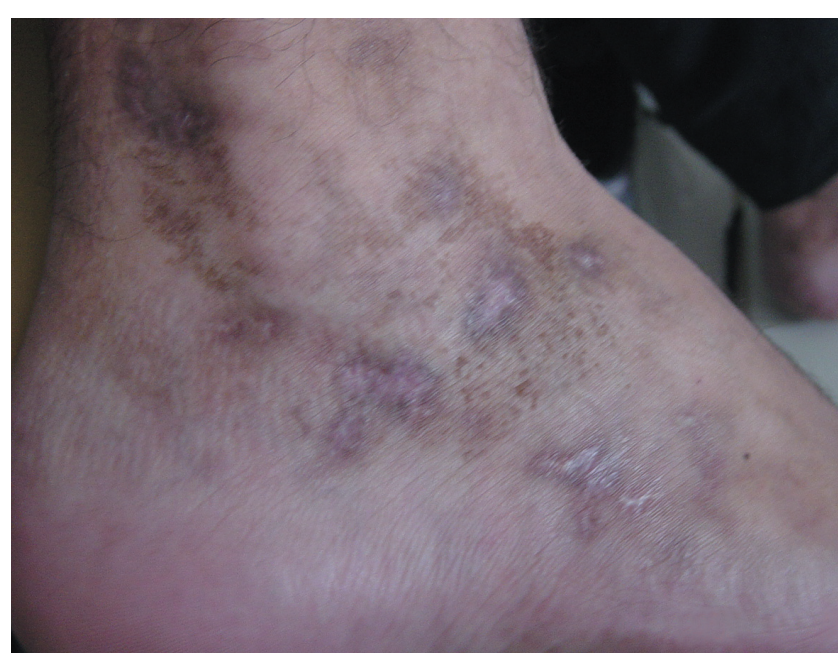

FigurA 2: Melhora com cicatrização das lesões após uso da Igiv cas, pápulas e úlceras variando de 0,2 a $1,5 \mathrm{~cm}$ de diâmetro e rede vascular, atingindo ambos os membros inferiores. Foram solicitados hemograma, bioquímica do sangue, sumário de urina, fator reumatóide, proteína $\mathrm{C}$ reativa, ASLO, níveis séricos de $\mathrm{C} 3$ e $\mathrm{C} 4$, antígenos nucleares, anticorpo antiDNA, anticardiolipídeos, crioaglutinina, tempo de protrombina, tromblosplastina parcial, proteínas S e C, plasminogênio, fator V de Leiden, FAN, anti-Ro, antiLa, radiografia de tórax, ultra-sonografia abdominal, ultra-som dúplex e fotopletismografia digital, todos com resultados dentro dos parâmetros normais. Ao exame histológico da biópsia observou-se pele com epiderme eutrófica, ortoceratótica. Na derme, observaram-se alguns vasos com paredes espessadas e sinais de degeneração hialina, parede vascular com exsudação mononuclear. Utilizou-se Igiv na dose de $0,5 \mathrm{~g} / \mathrm{kg}$ de peso por dia durante três dias consecutivos por mês. Nesse caso foram utilizados três ciclos, sem efeitos colaterais e evolução com resolução completa das lesões ulceradas. O tratamento foi suspenso, conforme orientação do protocolo. A terapia local consistiu apenas em emolientes e limpeza das feridas. Doze meses depois da suspensão da Igiv (Figura 2) o paciente encontrava-se bem e sem recidiva da doença.

Acredita-se que o depósito capilar de fibrina e a formação de trombos são as maiores causas do infarto de doenças da derme e epiderme. Histologicamente a VL é caracterizada por hialinização segmentar, proliferação endotelial, deposição de fibrina e formação de trombos na derme papilar e reticular superficial.

Anormalidades na coagulação sistêmica parecem estar envolvidas em mecanismos fisiopatológicos da VL. Nesse contexto, deficiência concomitante de vitamina C, mutação do fator $\mathrm{V}$ e mutação do gene da protrombina têm sido descritos. ${ }^{4,6} \mathrm{O}$ paciente em questão, porém, não apresentou coagulação anormal.

As terapêuticas para VL são usualmente focadas em drogas fibrinolíticas, antitrombóticos e vasodilatadores. Aspirina, pentoxifilina, prostaciclina, plasminogênio tissular ativado, heparina de baixo peso molecular, dipiridamol, ácido nicotínico, e fenformina têm sido testados. ${ }^{2,3}$

Ho e Yang relataram dois pacientes com LV que responderam a psoralênicos sistêmicos com ultravioleta A e com methoxsalen. Hsiao e Chiu utilizaram danazol, um androgênio sintético com potencial efeito fibrinolítico, em sete pacientes. O uso da câmara hiperbárica tem sido descrito. ${ }^{2,3,8}$

$\mathrm{Na}$ dermatologia, a Igiv tem sido usada em várias doenças auto-imunes, predominantemente doenças bolhosas, como pênfigo vulgar e penfigóide bolhoso, e também as colagenoses como as vasculites. ${ }^{5,7} \mathrm{O}$ modo de ação não é completamente entendido, mas modulação da produção de citocinas, neutralização dos patógenos envolvidos nas doenças auto-imunes, inibição do sistema de complemento e bloqueio dos receptores dão-se por meio de anticorpos antiFaz.,

A Igiv é usualmente bem tolerada. Efeitos adversos, como cefaléia, calafrios, febre, náuseas, vômitos, dispnéia e taquicardia, ocorrem em menos de 5\% dos pacientes tratados. São raros os episódios de reação anafilática, falência renal e anemia hemolítica. ${ }^{1,8}$

$\mathrm{O}$ paciente descrito não respondeu às estratégias prévias de tratamento e mostrou excelente resposta à Igiv sem maiores efeitos colaterais. A resposta foi rápida, completa e persistente, tendo o paciente seguido o tratamento proposto no protocolo. 


\section{REFERÊNCIAS}

1. Calamia KT, Balabanova M, Perniciaro C, Walsh JS. Livedo (livedoid) vasculitis and the factor $\mathrm{V}$ Leiden mutation: additional evidence for abnormal coagulation. J Am Acad Dermatol. 2002;46:133-7.

2. Sami N, Bhol KC, Ahmed RA. Influence of intravenous immunoglobulin therapy on autoantibody titers to desmoglein 3 and desmoglein 1 in pemphigus vulgaris. Eur J Dermatol. 2003;13:377-81.

3. Yang CH, Ho HC, Chan YS, Liou LB, Hong HS, Yang LC. Intractable livedoid vasculopathy successfully treated with hyperbaric oxygen. Br J Dermatol. 2003;149:647-52.

4. Gotlib J, Kohler S, Reicherter P, Oro AE, Zehnder JL. Heterozygous prothrombin G20210A gene mutation in a patient with livedoid vasculitis. Arch Dermatol. 2003;139:1081-3.

5. Hairston BR, Davis MD, Gibson LE, Drage LA. Treatment of livedoid vasulopathy with low-molecular-weight heparin: report of 2 cases. Arch Dermatol. 2003;139:987-90.

6. Schanz S, Ulmer A, Fierlbeck G. Intravenous immunoglobulin in livedo vasculitis: A new treatment option? J Am Acad Dermatol. 2003;49:555-6.
7. Levy Y, Sherer Y, Ahmed A, Langevitz P, George J, Fabbrizzi F. A study of 20 SLE patients with intravenous immunoglobulin: clinical and serologic response. Lupus. 1999;8:705-12.

8. Ravat FE, Evans AV, Russell-Jones R. Response of live doid vasculitis to intravenous immunoglobulin. $\mathrm{Br} \mathrm{J}$ Dermatol. 2002;147:166-9.

9. Ulmer A, Kötter I, Pfaff A, Fierlbeck G. Efficacy of pulsed intravenous immunoglobulin therapy in mixed connec tive tissue disease. J Am Acad Dermatol. 2002;46:123-7.

ENDEREÇO PARA CORRESPONDÊNCIA / MAILING ADDRESS:

Jader Freire Sobral Filbo

Avenida Epitácio Pessoa, 2526 Tambauzinbo

58045000 - João Pessoa - PB

Tel: 083 - 32443136 / 083 - 99813050

E-mail: jaderfreire@uol.com.br

Como citar este artigo / How to cite this article: Sobral JFF, Valdek COM, Rodrigues LTD. Tratamento de vasculopatia livedóide com imunoglobulina intravenosa. An Bras Dermatol. 2008;83(4):372-4. 